\title{
Yield and Profitability of Modified Spanish Bush and Y-trellis Training Systems for Peach
}

\author{
Tiziano Caruso \\ Department of Agricultural and Forest Sciences, Università degli Studi di \\ Palermo, Palermo, Italy
}

Francesco Guarino

OSAS-OPSIBARIT-CAMPOVERDE, Castrovillari, Italy

\section{Riccardo Lo Bianco ${ }^{1}$ and Francesco Paolo Marra \\ Department of Agricultural and Forest Sciences, Università degli Studi di Palermo, Palermo, Italy}

Additional index words. fixed costs, fruit size, management labor, pay-back period, profit, Prunus persica, unit price

\begin{abstract}
Peach trees trained to modified spanish bush (MSB) and Y-trellis (Y) were evaluated and compared in the Mediterranean settings of southern Italy. The observations included two peach (Rich May and Summer Rich) and two nectarine (Big Bang and Nectaross) cultivars. In the MSB system, trees were spaced at $4.5 \times 2.5 \mathrm{~m}(888$ trees/ha), whereas in the $Y$ system, trees were spaced at $5.5 \times 2 \mathrm{~m}(909$ trees/ha). Costs at planting, yield per tree, fruit size grade, unit price of sold peaches for each size grade, amount and cost of materials and labor for cultural management, and grower's profit were quantified throughout all 6 years from planting and at full crop (year 4-6). Fixed costs of the MSB system were $45 \%$ lower at planting, $11 \%$ lower for fertilization, and $33 \%$ lower for pest control than in the Y system. Regardless of cultivar, the MSB system reported 19\% lower yields, $29 \%$ less management labor, and $12 \%$ higher labor efficiency (kg fruit/h) than the Y system. The yield gap between the two systems tended to decrease after the 5 th year. A greater percentage of fruit fell into large size categories in the MSB than in the Y system. Fruit unit value and yearly profit were similar in the two systems. Even for the most profitable cultivar under the $Y$ system (i.e., Nectaross), the time needed to pay off the additional investment for establishing a $Y$ by its additional profit was $\approx 11$ years, indicating an advantage of the $Y$ system over the MSB only by the 12th year from planting. Yield trends, along with the high initial investment and management labor and costs in the $Y$ system, indicate better financial performance and more sustainable production in the MSB than in the $Y$ system.
\end{abstract}

Over the past 50 years, several planting systems for peach [Prunus persica (L.) Batsch.] orchards have been developed to reach high early yields and improved fruit quality. In the 1980s and 1990s, orchard planting systems were based on high tree densities ranging from 1000 to 1500 trees/ha (Loreti and Massai, 2002). However, increasing planting density alone does not provide an efficient tool to increase yield and improve fruit quality, as planting density and yield are not linearly related and a threshold can be found beyond which a further increase in density may not result in greater yield (Sansavini and Corelli-Grappadelli, 1997). Indeed, with age high-density orchards may

Received for publication 21 Apr. 2015. Accepted for publication 29 May 2015.

Research carried out in this study was funded by the Regional grant "IGP pesco" from the Department of Agriculture of the Sicilian Government.

${ }^{1}$ Corresponding author. E-mail: riccardo.lobianco@ unipa.it. pose serious problems for canopy management and ultimately compromise fruit quality (Caruso et al., 1999; Jackson, 1980; Marini et al., 1991; Policarpo et al., 2006).

Over the past 30 years, double wall systems such as Tatura trellis and its variants [Y-trellis (Y), perpendicular V, Kearney Agricultural Center perpendicular V, etc.] have been the main focus of detailed studies and several trials (DeJong et al., 1994). The primary advantage of $\mathrm{V}$ or $\mathrm{Y}$ systems is high yields per hectare (Caruso et al., 1998b; Van den Ende et al., 1987), high yield efficiency (Iannini et al., 2002), high levels of light interception (Grossman and DeJong, 1998), reduced incidence of fungal diseases (Rufato et al., 2004), and improved fruit quality (increased peel color and soluble solid content and more uniform fruit size) (Caruso et al., 1998a), especially in areas with high levels of irradiance. Perpendicular V or Y systems typically allow for higher tree densities than other open center or vase-shaped canopies; they also show better light interception than spherical canopies or vertical systems and improve light distribution within the canopy because of their two-dimensional light exposure (Caruso et al., 1997; De Salvador and DeJong, 1989; Wagenmakers, 1991). On the other hand, labor efficiency or yield per unit of labor is generally low in those systems due to the high establishment and management costs, which offset fruit yield and quality improvements over similar crop values and profits of vase-shaped systems (DeJong et al., 1999). In addition, openvase systems are more profitable than central leader systems (Marini and Sowers, 2000).

A recent modification of the standard vase is the spanish bush, initially developed in Spain for cherry (Prunus avium L.) and subsequently extended to peach orchards. In this variant, trees are trained to open center by leaving initially six to seven branches, gradually reduced to a final number of four main branches by the 5 th year. The vase-shaped canopy is contained within $2.5 \mathrm{~m}$ of height by frequent toppings; the result is a relatively compact tree suitable for medium-high density plantings, good light interception by the fairly open canopy, and significantly reduced training and management labor (Long, 2001). Spanish bush has been recently modified and adapted to cultural conditions of southern Italy; the resulting modified spanish bush (MSB) system seems to be a promising choice for new peach plantings across similar regions. Although to date no yield data are available in the literature for the spanish bush or its modifications, trials on similar compact, open-shaped systems have shown greater production per hectare and fruit size under protected culture (Bellini et al., 2000) and more uniform fruit size (Farina et al., 2005) compared with Y systems.

The right choice of training system and planting density must take into account the costs involved for orchard establishment and management. In this study, a yield and economic analysis was performed on peach and nectarine cultivars to compare $\mathrm{Y}$ and MSB orchard systems.

\section{Materials and Methods}

The study was conducted in orchards of the OSAS-OPSIBARIT-CAMPOVERDE cooperative located near Castrovillari $\left(39^{\circ} 49^{\prime} \mathrm{N}, 16^{\circ} 12^{\prime} \mathrm{E}\right.$ and $90 \mathrm{~m}$ above sea level), in southern Italy. The observations included two peach (Rich May and Summer Rich) and two nectarine (Big Bang and Nectaross) cultivars and were carried out on four plots of size ranging from 3.5 to 7.5 ha and located within $2 \mathrm{~km}$. The cooperative extends throughout a plain valley area with uniform clay loam soils composed of $47 \%$ sand, $31 \%$ silt, and $22 \%$ clay. Within each cultivar plot, two neighboring subplots were selected, one with trees trained to MSB and the other with trees trained to $\mathrm{Y}$.

The MSB system in this study is a modification of the spanish bush developed with the collaborative effort of the cooperative and extension services of southern Italy. In this system, canopies were trained to four main branches since the 2nd year, while in trees trained to the spanish bush a higher number of 
branches is left initially to be gradually reduced to four by the 5th year. As a consequence, the MSB variant produces less, but better quality fruit and is less labor intensive in the first years compared with the spanish bush. The MSB trees were lined and planted mechanically $(15 \mathrm{~h} / \mathrm{ha})$, trained to a height of $\approx 2.3 \mathrm{~m}$ and the center open at $70^{\circ}$, with spacings of $4.5 \mathrm{~m}$ between rows and $2.5 \mathrm{~m}$ on the row ( 888 trees/ha), and a distance of $2 \mathrm{~m}$ between canopy tops of adjacent rows; the main scaffold was set at $50 \mathrm{~cm}$ from the ground.

In the $\mathrm{Y}$ system, trees were trained to a height of $\approx 3.3 \mathrm{~m}$, an angle of $75^{\circ}$ between the two main branches, with spacings of $5.5 \mathrm{~m}$ between rows and $2 \mathrm{~m}$ on the row (909 trees/ ha), and a distance of $1.5 \mathrm{~m}$ between canopy tops of adjacent rows; the main scaffold was set at $50 \mathrm{~cm}$ from the ground. In addition to the two main branches perpendicular to the row direction, two secondary branches were left on each side running parallel to the row but in opposite directions; these branches were located within $1 \mathrm{~m}$ from the main scaffold and renewed every year to maintain production in the lower portion of the canopy. Because of crotch angle, length of main branches, and presence of secondary branches, the Y was supported by a system of poles and three levels of wiring. Trees were planted manually $(150 \mathrm{~h} / \mathrm{ha})$ to get more precise lining with the support system.

All trees were planted in 2007, grafted on Cadaman rootstock and received conventional cultural practices and integrated pest management. Trees were drip irrigated via a single line per row using two drippers per tree and fertilizers were supplied in the irrigation water. MSB trees were chemically weeded along the row and irrigation lines were laid on the ground. On the contrary, because of the presence of low secondary branches, $\mathrm{Y}$ trees were soil worked and

Table 1. Fixed and annual costs (€/ha) for modified spanish bush (MSB) and Y-trellis (Y) training systems in 2007 near Castrovillari, Italy.

\begin{tabular}{lcr}
\hline Operations and materials & MSB & \multicolumn{1}{c}{ Y } \\
\hline Planting & 6,552 & 11,898 \\
Deep plowing/fertilizing & 1,000 & 1,000 \\
Grafted plants & 3,552 & 3,636 \\
Lining/planting & 200 & 1,200 \\
Trellis system & - & 3,680 \\
Irrigation system & 1,800 & 2,382 \\
Fertilization & 387 & 434 \\
Pest control & 800 & 1,200 \\
Total & 7,739 & 13,532 \\
\hline
\end{tabular}

Table 2. Partitioning of labor (\%) among main cultural practices for the four cultivar in trial trained to modified spanish bush (MSB) and Y-trellis (Y) training systems near Castrovillari, Italy. Data are averages of the 6 years.

\begin{tabular}{llcccr}
\hline & \multicolumn{1}{c}{ Cultivar } & Topping & Pruning & Fruit thinning & Harvest \\
\hline MSB & Big Bang & 1.9 & 30.2 & 24.1 & 43.8 \\
& Nectaross & 2.3 & 17.9 & 23.6 & 56.2 \\
& Rich May & 2.8 & 41.2 & 12.6 & 43.4 \\
& Summer Rich & 2.6 & 22.0 & 22.0 & 53.4 \\
& & & & 22.5 & 36.9 \\
Y & 0 & 40.6 & 19.1 & 42.2 \\
& Big Bang & 0 & 38.7 & 19.6 & 39.3 \\
& Nectaross & 0 & 41.2 & 20.0 & 42.4 \\
\hline
\end{tabular}

irrigation lines were raised to $\approx 30 \mathrm{~cm}$. Integrated pest control was performed using low-volume sprayers at 1 or $1.5 \mathrm{~m}^{3} \cdot \mathrm{ha}^{-1}$ per year for MSB or Y system, respectively, because of differences in canopy volumes (Y 30\% larger than MSB). MSB trees were topped mechanically, twice a year during the first 2 years from planting, once a year thereafter; selective hand pruning followed topping. $Y$ trees were winter and green pruned only by hand leaving $80-100$ fruiting shoots $(60 \mathrm{~cm}$ long) per tree depending on cultivar fertility. Fruit of MSB trees were hand thinned leaving one fruit every $15 \mathrm{~cm}$ of shoot in early-ripening cultivars (small fruit) and one fruit every $10 \mathrm{~cm}$ in late-ripening cultivars (large fruit). In Y trees, differential thinning (Caruso et al., 2001) was carried out by hand leaving one fruit every $10 \mathrm{~cm}$ of shoot in the top part of the canopy and one fruit every $15 \mathrm{~cm}$ in the bottom part of the canopy. The general target was to leave 200$220 \mathrm{fruit} /$ tree in MSB, and 260-280 fruit/tree in the $\mathrm{Y}$ system. Harvest operations were carried out by hand, from the ground in MSB and with the aid of picking platforms in Y. As indicated, different levels of mechanization were involved in the cultural management of the two training forms.

Yield, fruit size grade, unit price (UP) of sold peaches for each size grade, materials and labor for cultural management and associated costs, fixed costs at planting (FC), and grower's profit $(\mathrm{P})$ were quantified on each plot and expressed on an hectare basis using average data per year (4th-6th), training system and cultivar, or cumulative data across all 6 years per cultivar and training system. Labor efficiency was calculated as the amount of fruit produced divided by the total amount of labor requested for all annual operations. Fruits were machine graded by separating them into seven size categories, namely $<50,51-55,56-60$, $61-66,67-72,73-79$, and 80-89 mm. Yield included also unmarketable fruit.

Specifically, P was calculated as (UP VC) $\times$ yield in euro $(€) / h a$, where $\mathrm{VC}$ is variable costs as the sum of production costs (all cultural practices including pest control and fertigation) divided by yield $\left(\mathrm{kg} \cdot \mathrm{ha}^{-1}\right)$ in $€ / \mathrm{kg}$. The pay-back period (PBP), indicating the time in years that it takes to pay off the additional investment needed to establish the $\mathrm{Y}$ system by its additional profit, was calculated as $\left(\mathrm{FC}_{\mathrm{Y}}-\mathrm{FC}_{\mathrm{MSB}}\right) /$ $\left(\mathrm{P}_{\mathrm{Y}}-\mathrm{P}_{\mathrm{MSB}}\right)$, using in this case the average $\mathrm{P}$ of all 6 years (Satienperakul et al., 2009).
Average exchange rate for the years of trial was US\$1.35 for $€ 1$.

Data were collected for six consecutive years from 2008 to 2013. The experimental design was a randomized plot with year as a random replicate. Yield and labor data were analyzed using $\mathrm{R}$ (The $\mathrm{R}$ Foundation for Statistical Computing, Vienna, Austria) procedures with training system and cultivar as main factors, their interaction as the sole interaction, and year as a random replicate factor in the model. When appropriate, Tukey's test at $P<0.05$ was used to separate means. Labor, yield, production value, and profit data were also cumulated over the 6 years and means of the two training forms were compared by $t$ test. Distribution of fruit into size categories was analyzed by fitting Gaussian models with QtiPlot software (Vasilief, 2013) and comparing curve centers (peaks) by $t$ test (between training systems) or analysis of variance (ANOVA) (among cultivars). The Gaussian model adopted to fit data was:

$$
\begin{aligned}
y= & y_{0}+\text { area } \times[(2 / \pi) / \text { width }]^{0.5} \\
& \times \exp \left\{-2\left[\left(x-x_{\text {center }}\right) /(\text { width })\right]^{2}\right\}
\end{aligned}
$$

In this case, model parameters were estimated using a continuous scale from 1 to 7 (from small to large fruit) in place of the seven size categories.

\section{Results and Discussion}

As expected, fixed costs were lower in the MSB than in the Y system, and specifically $45 \%$ lower at planting, $11 \%$ lower for fertilization, and $33 \%$ lower for pest control (Table 1). Differences of fertilization and pest management costs were due to differences in planting density and canopy height, respectively. Also, planting operations were entirely mechanized for MSB, although done by hand, and therefore more expensive, in the $\mathrm{Y}$ system because of the presence of the trellis structure. Overall, 43\% higher fixed costs were associated to the $\mathrm{Y}$ system compared with the MSB system. This result was mostly due to the cost of labor and support structures needed to establish the trellis, as well as to higher tree density and bigger canopies associated to the $\mathrm{Y}$ compared with the MSB system.

As for partitioning of labor among main cultural practices, labor needed for fruit thinning was similar in both systems, whereas a greater percentage of labor was used for pruning in the $\mathrm{Y}$ system and for harvesting in the MSB system (Table 2). Among cultivars, Nectaross and Summer Rich required less labor for pruning and more for harvesting than Big Bang and Rich May. Also labor associated with cultural practices and tree management was $29 \%$ greater in the $\mathrm{Y}$ than in the MSB system, regardless of cultivar; whereas Rich May required less labor than the other cultivars, regardless of training system (Table 3). The latter was primarily due to differences in yield, with 'Rich May' being less productive than the other cultivars. Pruning generally requires 
Table 3. Average (from year 4 to 6 ) and cumulative (from year 1-6) labor needed for main cultural practices $\left(\mathrm{h} \cdot \mathrm{ha}^{-1}\right.$ per year) and yield (t.ha ${ }^{-1}$ per year) of the four cultivars in trial trained to modified spanish bush (MSB) and Y-trellis (Y) systems near Castrovillari, Italy.

\begin{tabular}{lcrc}
\hline Cultivar & MSB & Y & \\
\hline Big Bang & 768 & 989 & $\mathrm{a}^{\mathrm{z}}$ \\
Nectaross & 800 & 1,140 & $\mathrm{a}$ \\
Rich May & 515 & 780 & $\mathrm{~b}$ \\
Summer Rich & 729 & 1,039 & $\mathrm{a}$ \\
$\quad$ Average & 703 & 987 & $P<0.001$ \\
Cumulative & 2,482 & 3,584 & $P<0.001$ \\
\multicolumn{4}{r}{ Yield } \\
Big Bang & 21.7 & 24.4 & $\mathrm{~b}^{\mathrm{z}}$ \\
Nectaross & 40.2 & 52.8 & $\mathrm{a}$ \\
Rich May & 10.9 & 18.7 & $\mathrm{c}$ \\
Summer Rich & 29.4 & 30.1 & $\mathrm{~b}$ \\
$\quad$ Average & 25.6 & 31.5 & $P=0.008$ \\
Cumulative & 87.9 & 111.3 & $P=0.132$
\end{tabular}

${ }^{2}$ Letters indicate differences among cultivars by Tukey's test at $P<0.05$, whereas $P$ values indicate significance levels for training system effect (ANOVA). Nonsignificant training system $\times$ cultivar interactions.

more skilled labor than harvesting, making the $\mathrm{Y}$ system management even more difficult and expensive. Overall, establishment costs affected the training system economy more than management costs because of expenses associated with trellising; higher planting density and taller canopies in the $\mathrm{Y}$ than in the MSB system determined most of the cost differences during management.

In all observed cultivars, the $\mathrm{Y}$ system exhibited greater yields than the MSB system, with an average 19\% difference in favor of the former (Table 3). Previous studies had already documented higher yields in the $\mathrm{Y}$ system compared with central leader (Caruso et al., 1998b) or standard vase (Grossman and DeJong, 1998) and attributed the increased cropping to greater and better light interception (De Salvador and DeJong, 1989; Grossman and DeJong, 1998). Yet, it is worth to mention that cumulated yields (i.e., first 3 years included) were not statistically different between the two systems (Table 3 ) and that the yield gap between the two systems tended to decrease after the 5th year (Fig. 1). 'Nectaross' trees exhibited the highest and 'RichMay' trees the lowest yields (Table 3), although yield trends show that only 'Nectaross' was distinctively producing more than the other cultivars at the full production orchard stage (Fig. 1).

Fruit distribution into size categories followed Gaussian trends with peaks generally centered on intermediate size classes (Fig. 2). Among cultivars, Nectaross and Summer Rich generally centered their distribution on larger fruit size classes than Big Bang and Rich May (Fig. 2; Table 4), suggesting overall larger fruits in the former cultivars. This is a genetic difference mostly associated to fruit maturation precocity, i.e., 'Big Bang' and 'Rich May' fruit mature in early June, whereas 'Summer Rich' and 'Nectaross' mature between the end of July and the beginning of August.
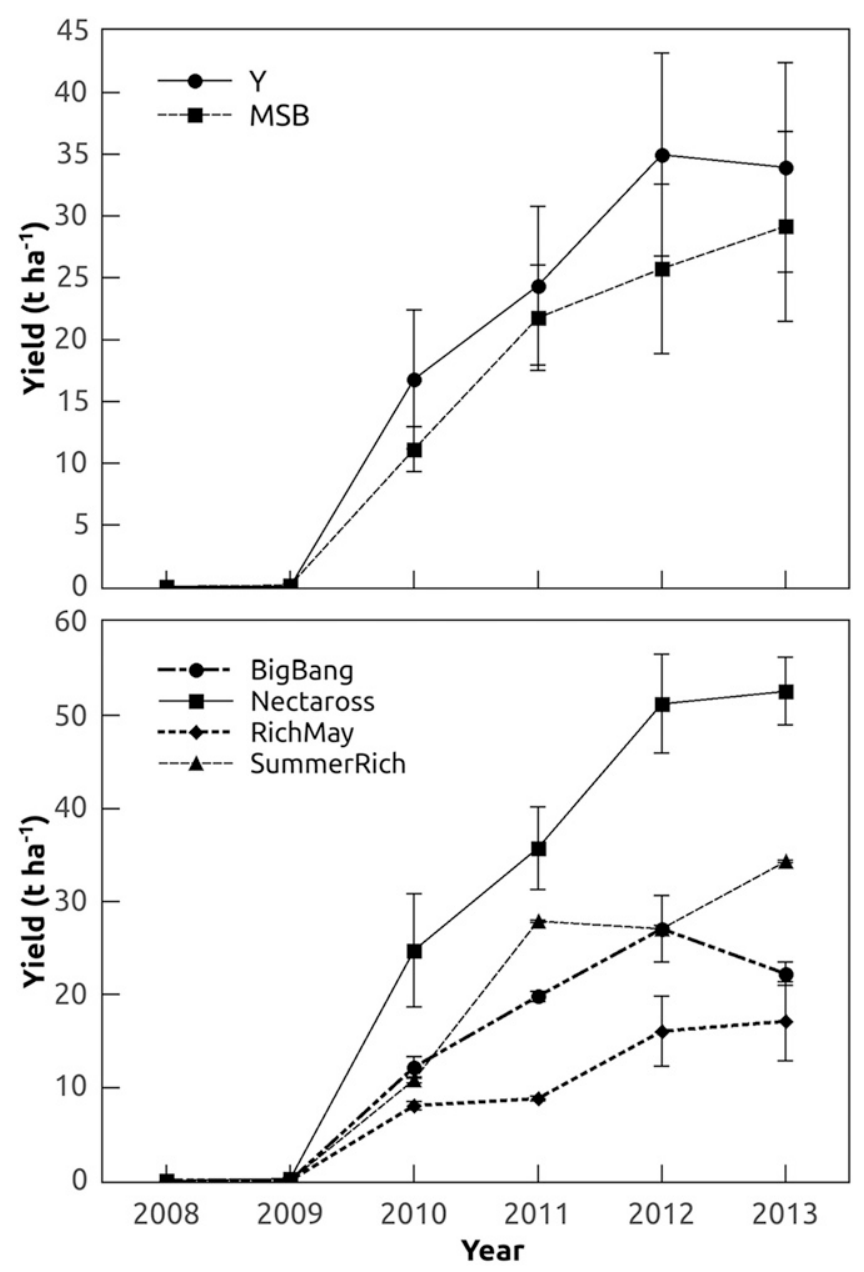

Fig. 1. Yield trends of the four cultivars in trial trained to modified spanish bush (MSB) and Y-trellis (Y) systems near Castrovillari, Italy, from the first (2008) to the 6th (2013) year from planting. Error bars represent standard errors of the means.

Generally, trees trained to the MSB system produced a greater percentage of fruit of the larger size categories (Fig. 2), indicating that fruit were bigger in the MSB than in the Y system. Further proof of the latter is the greater curve center value for MSB compared with $\mathrm{Y}$ in all cultivars (Table 4), indicating peaking of the MSB system at larger size categories than the $\mathrm{Y}$ system. Greater fruit size and lower yields in the MSB compared with the $\mathrm{Y}$ system suggest that there were fewer fruits on the tree, and probably a better leaf to fruit ratio, in the MSB than in the Y system. An inverse relationship between peach crop load and fruit size is expected and it has been documented in several studies (Berman and DeJong, 1996; Blanco et al., 1995; Inglese et al., 2002; Naor et al., 1999; Rowe and Johnson, 1992). As a result of yield levels and amount of labor required, the MSB system was $\approx 12 \%$ more efficient than the $\mathrm{Y}$ system in terms of kilograms of fruit produced per hour of labor. The difference in favor of the MSB system was particularly evident in 'Summer Rich' trees with over a 30\% difference (Table 5). 'Nectaross' was generally the most labor efficient because of high yields.
Unit crop value was similar in the two training systems, but different among cultivars with values somewhat inversely related to yield (Table 6). These unit crop values were calculated after real market sales and were the result of several variables, including but not limited to fruit grade. Other factors affecting unit value were related to fruit type (nectarine vs. peach), maturation precocity and marketing period, as well as external and internal fruit quality (probably inversely related to yield). On the other hand, total production values were directly related to yields, with 'Nectaross' having the highest and 'Rich May' the lowest values (Table 7). Contrary to yields, there was no significant difference between the two systems in terms of average production values, but a nearly significant difference in terms of cumulated production value. The resulting profits varied greatly and no statistical difference was found among cultivars or training systems (Table 7). Nevertheless, average differences among cultivars ranked 'Rich May' as the least profitable cultivar with a profit loss of $\approx € 3000$ every year compared with the other cultivars if trained to MSB (Table 7). Low profit in 'Rich May' trained to MSB was mostly due to low yields and in part to small fruit. 


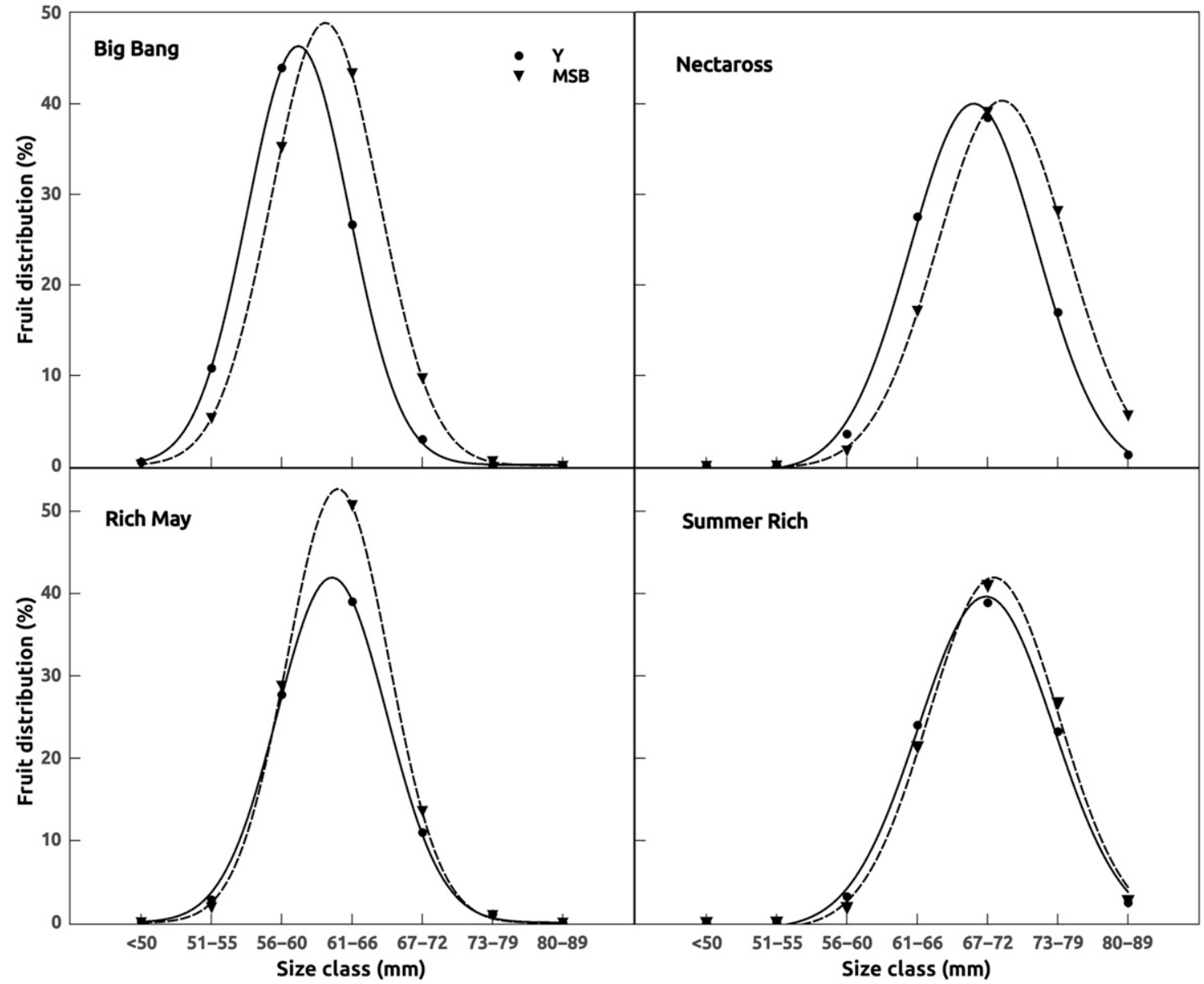

Fig. 2. Distribution of peach fruit (average of year 4-6) into various size categories for the four cultivars in trial trained to modified spanish bush (MSB) and Y-trellis (Y) training systems near Castrovillari, Italy. Curves fitted according to Gaussian model $y=y_{0}+$ area $\times[(2 / \pi) / \text { width }]^{0.5} \times \exp \left\{-2\left[\left(x-x_{\text {center }}\right) /(\text { width })\right]^{2}\right\}$.

Table 4. Curve peaks (centers) of fruit distribution models into size categories for the four cultivars in trial trained to modified spanish bush (MSB) and Y-trellis (Y) systems near Castrovillari, Italy. Means are expressed on a continuous scale from 1 to 7 corresponding to the seven size classes monitored and going from small to large fruit. The Gaussian model adopted to fit data were $y=y_{0}+$ area $\times \sqrt{ }(2 / \pi) /$ width $\times \exp$ $\left\{-2\left[\left(x-x_{\text {center }}\right) /(\text { width })\right]^{2}\right\}$.

\begin{tabular}{lcrr}
\hline Cultivar & MSB & Y & $P^{z}$ \\
\hline Big Bang & $2.62 \mathrm{c}$ & $2.24 \mathrm{c}$ & $<0.001$ \\
Nectaross & $4.21 \mathrm{a}$ & $3.81 \mathrm{a}$ & $<0.001$ \\
Rich May & $2.80 \mathrm{~b}$ & $2.62 \mathrm{~b}$ & $<0.001$ \\
Summer Rich & $4.09 \mathrm{a}$ & $3.98 \mathrm{a}$ & 0.048
\end{tabular}

${ }^{z} P$ values indicate significance levels of $t$ tests between training systems for each cultivar, whereas letters indicate differences among cultivars for each training system.

Table 5. Labor efficiency (average of year 4-6, $\mathrm{kg} \cdot \mathrm{hr}^{-1}$ ) for the four cultivars in trial trained to modified spanish bush (MSB) and Y-trellis (Y) systems near Castrovillari, Italy. Significant training system $\times$ cultivar interaction $(P=0.008)$.

\begin{tabular}{lcc}
\hline Cultivar & MSB & Y \\
\hline Big Bang & 28.4 & 24.4 \\
Nectaross & 50.0 & 46.5 \\
Rich May & 21.5 & 24.2 \\
Summer Rich & 41.4 & 28.9 \\
$\quad$ Average & 35.3 & 31.0 \\
& & HSD $^{\mathrm{z}}=4.12$ \\
\hline
\end{tabular}

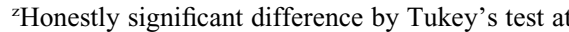
$P<0.05$.

When yearly profits were calculated using the data of all 6 years from planting, 'Nectaross' was more profitable under the $\mathrm{Y}$ system than under the MSB system (data not shown). Even for the most profitable cultivar under the Y system (i.e., Nectaross), the PBP (years needed to pay off the additional investment of establishing a $\mathrm{Y}$ by its additional profit) was almost 11 years, indicating an advantage of the $\mathrm{Y}$ system over the MSB by the 12th year from planting, and only for 'Nectaross'. Such timing is definitely unsustainable for any fruit grower.

\section{Conclusions}

Overall, trees trained to MSB produced fruit of similar value and yearly profit compared with trees trained to Y. Hence, the high amount/cost of labor to manage $Y$ trees along with the high initial costs to establish the $\mathrm{Y}$
Table 6. Unit crop value ${ }^{z}$ (average of year 4-6, $€ / \mathrm{kg}$ ) for the four cultivars in trial trained to modified spanish bush (MSB) and Y-trellis (Y) systems near Castrovillari, Italy.

\begin{tabular}{lccc}
\hline Cultivar & MSB & Y & \\
\hline Big Bang & 0.57 & 0.51 & $\mathrm{a}^{\mathrm{y}}$ \\
Nectaross & 0.32 & 0.27 & $\mathrm{~b}$ \\
Rich May & 0.62 & 0.50 & $\mathrm{a}$ \\
Summer Rich & 0.37 & 0.41 & $\mathrm{ab}$ \\
$\quad$ Average & 0.47 & 0.42 & $P=0.355$
\end{tabular}

${ }^{\mathrm{z}}$ Average exchange rate for the years of trial was US\$1.35 to $€ 1$.

'Letters indicate differences among cultivars by Tukey's test at $P<0.05$, whereas $P$ value indicate significance level for training system effect (ANOVA). Nonsignificant training system $\times$ cultivar interaction $(P=0.730)$.

system indicate a better financial performance of the MSB compared with the Y system. In addition, the high amount of labor, fuel, and materials involved in the establishment and management of the $\mathrm{Y}$ system clearly indicates more environmentally sustainable conditions in the MSB than in the $\mathrm{Y}$ system. Expected trends for the years following the sixth and up to the average peach orchard life (12th-15th) are likely to confirm the observed results, or even increase the economical advantage of the MSB over the Y because MSB trees may 
Table 7. Average (from year 4 to $6, € /$ ha/year) and cumulative (from year 1 to $6, € /$ ha) production value and profit ${ }^{2}$ for the four cultivars in trial trained to modified spanish bush (MSB) and Y-trellis (Y) systems near Castrovillari, Italy.

\begin{tabular}{lccc}
\hline Cultivar & MSB & $\mathrm{Y}$ \\
\hline Big Bang & Production value \\
Nectaross & 12,354 & 11,964 & $\mathrm{ab}^{\mathrm{y}}$ \\
Rich May & 12,744 & 13,894 & $\mathrm{a}$ \\
Summer Rich & 6,808 & 9,395 & $\mathrm{~b}$ \\
$\quad$ Average & 10,609 & 12,016 & $\mathrm{ab}$ \\
Cumulative & 36,273 & 11,817 & $P=0.321$ \\
\multicolumn{4}{c}{ Profit } \\
Big Bang & 5,778 & 4,504 & $P=0.058$ \\
Nectaross & 6,180 & 5,443 & $\mathrm{a}^{\mathrm{y}}$ \\
Rich May & 1,815 & $\mathrm{a}, 065$ & $\mathrm{a}$ \\
Summer Rich & 4,622 & 4,133 & $\mathrm{a}$ \\
Average & 4,598 & 4,286 & $P=0.879$ \\
Cumulative & 11,144 & 11,237 & $P=0.939$ \\
\hline
\end{tabular}

${ }^{\mathrm{z}}$ Average exchange rate for the years of trial was US $\$ 1.35$ to $€ 1$.

${ }^{y}$ Letters indicate differences among cultivars by Tukey's test at $P<0.05$, whereas $P$ values indicate significance levels for training system effect (ANOVA). Nonsignificant training system $\times$ cultivar interactions.

reach their full productive potential later than Y trees.

\section{Literature Cited}

Bellini, E., D. Falqui, and O. Musso. 2000. Comparison between two training systems in peach protected culture in Sicily. Acta Hort. 513:427-433.

Berman, M.E. and T.M. DeJong. 1996. Water stress and crop load effects on fruit fresh and dry weights in peach (Prunus persica). Tree Physiol. 16:859-864.

Blanco, A., A. Pequerul, J. Val, E. Monge, and J. Gomez-Aparisi. 1995. Crop-load effects on vegetative growth, mineral nutrient concentration and leaf water potential in Catherine peach. J. Hort. Sci. 70:623-629.

Caruso, T., C. Di Vaio, P. Inglese, and L.S. Pace. 1998a. Crop load and fruit quality distribution within canopy of 'Spring Lady' peach trees trained to 'central leader' and 'y shape'. Acta Hort. 465:621-628.

Caruso, T., D. Giovannini, F.P. Marra, and F. Sottile. 1997. Two new planting systems for early ripening peaches (Prunus persica L. Batsch): Yield and fruit quality in four low-chill cultivars. J. Hort. Sci. 72:873-883.

Caruso, T., D. Giovannini, F.P. Marra, and F. Sottile. 1999. Planting density, above-ground drymatter partitioning and fruit quality in greenhouse-grown 'Flordaprince' peach (Prunus persica $\mathrm{L}$. Batsch) trees trained to 'freestanding Tatura'. J. Hort. Sci. Biotechnol. 74:547-552.

Caruso, T., P. Inglese, F. Sottile, and F.P. Marra. 1998b. Effect of planting system on productivity, dry-matter partitioning and carbohydrate content in above-ground components of 'Flordaprince' peach trees. J. Amer. Soc. Hort. Sci. 124:39-45.

Caruso, T.P.I., C.D. Vaio, and L.S. Pace. 2001. Effect of different fruit thinning patterns on crop efficiency and fruit quality for greenhouse forced May Glo nectarine trees. Acta Hort. 557:287-293.

DeJong, T.M., R.D. Kevin, J.F. Doyle, and R.S. Johnson. 1994. The Kearney Agricultural Center Perpendicular "V" (KAC-V) orchard system for peach and nectarines. HortTechnology 4:362-367.

DeJong, T.M., W. Tsuji, J.F. Doyle, and Y.L. Grossman. 1999. Comparative economic efficiency of four peach production systems in California. HortScience 34:73-78.

De Salvador, F.R. and T.M. DeJong. 1989. Observation of sunlight interception and penetration into the canopies of peach trees in different planting densities and pruning configurations. Acta Hort. 254:341-346.

Farina, V., R. Lo Bianco, and P. Inglese. 2005 Vertical distribution of crop load an fruit quality within vase- and Y-shape canopies of 'Elegant Lady' peach. HortScience 40:587591.

Grossman, Y.L. and T.M. DeJong. 1998. Training and pruning system effects on vegetative growth potential, light interception, and cropping efficiency in peach trees. J. Amer. Soc. Hort. Sci. 123:1058-1064.

Iannini, C., C. Cirillo, B. Basile, and M. Forlani. 2002. Estimation of nectarine yield efficiency and light interception by the canopy in different training systems. Acta Hort. 592:357-365.

Inglese, P., T. Caruso, G. Gugliuzza, and L.S. Pace. 2002. Crop load and rootstock influence on dry matter partitioning in trees of early and late ripening peach cultivars. J. Amer. Soc. Hort. Sci. 127:825-830.
Jackson, J.E. 1980. Light interception and utilization by orchard systems. Hort. Rev. 2:208-267.

Long, L. 2001. Cherry training systems: Selection and development. Ore. State Univ., Pacific NW Ext. Publ. 543.

Loreti, F. and R. Massai. 2002. The high density peach planting system: Present status and perspectives. Acta Hort. 592:377-390.

Marini, R.P. and D. Sowers. 2000. Peach tree growth, yield, and profitability as influenced by tree form and tree density. HortScience 35:837-842.

Marini, R.P., D. Sowers, and M.C. Marini. 1991. Peach fruit quality is affected by shade during final swell of fruit growth. J. Amer. Soc. Hort. Sci. 116:383-389.

Naor, A., I. Klein, H. Hupert, Y. Grinblat, M. Peres, and A. Kaufman. 1999. Water stress and crop level interactions in relation to nectarine yield, fruit size distribution, and water potentials. J. Amer. Soc. Hort. Sci. 124:189-193.

Policarpo, M., G. Talluto, and R. Lo Bianco. 2006. Vegetative and productive responses of 'Conference' and 'Williams' pear trees planted at different in-row spacings. Sci. Hort. 190:322331.

Rowe, R.N. and R. Johnson. 1992. The interactions between fruit number, tree size and the yield and fruit size of Fantasia nectarine. Acta Hort. 315:171-176.

Rufato, L., A.D. Rossi, L. Picolotto, E. Parizoto, and J.C. Fachinello. 2004. Evaluation of vegetative and productive responses of two peach training systems ( $\mathrm{Y}$ system and central leader) in an ICM orchard. Acta Hort. 636:711-715.

Sansavini, S. and L. Corelli-Grappadelli. 1997. Yield and light efficiency for high quality fruit in apple and peach high density planting. Acta Hort. 451:559-568.

Satienperakul, K., P. Manochai, S. Ongprasert, W. Spreer, and J. Müller. 2009. Economic evaluation of different irrigation regimes in mango production in northern Thailand. Acta Hort. 831:293-300.

Van den Ende, B., D.J. Chalmers, and P.H. Jerie. 1987. Latest developments in training and management of fruit crops on Tatura Trellis. J. Amer. Soc. Hort. Sci. 105:695-699.

Vasilief, I. 2013. QTIPLOT: Data analysis and scientific visualisation. Univ. Utrecht, Utrecht, The Netherlands.

Wagenmakers, P.S. 1991. Planting system for fruit trees in temperate climates. Crit. Rev. Plant Sci. 10:369-385. 